\title{
New Zealand's Net Carbon Dioxide Emission Stabilisation Target
}

\author{
Robin Brasell
}

\section{$\mathrm{T}$}

THE New Zealand government has adopted a policy of a joint reliance upon carbon dioxide $\left(\mathrm{CO}_{2}\right)$ emission reductions and enhancement of carbon storage in plantation forests as the principal means of meeting its obligations under the Framework Convention on Climate Change (FCCC). The stated target is to stabilise net $\mathrm{CO}_{2}$ emissions at 1990 levels by 2000 . Few countries have interpreted their FCCC obligations to mean stabilisation of net emissions. But this is a sensible response in New Zealand, where emission reductions are relatively costly and the size of the plantation forest estate, which acts as a sink removing carbon from the atmosphere, is expected to continue increasing for some decades.

The present domestic regulatory framework includes uncertain and overlapping requirements for industrial emissions and effectively no controls over greenhouse gas emissions from transport or agriculture. The Minister for the Environment has therefore appointed a joint private- and public-sector working group to examine options for $\mathrm{CO}_{2}$ policy. Industries are concerned that no policy steps are taken beyond 'no regrets' (no net cost) levels unless clearly necessary, and that, if additional abatement actions are required, the options chosen recognise the relatively high cost of emission reductions in New Zealand and the comparative advantage that exists in the creation of additional carbon sinks.

\section{The Costs of $\mathrm{CO}_{2}$ Emission Reductions}

In recent years numerous papers and reports have been published concerning the impacts of reducing $\mathrm{CO}_{2}$ emissions on whole economies and particular sectors. The initial results suggested that emission reductions effected within relatively short timetables involved economic sacrifice. An early cxample of an analysis of the cost of New Zealand meeting an emission reduction target by means of a carbon tax was produced for the Electricity Corporation of New Zealand (ECNZ) by the Tasman Institute (1992). At that time there was considerable interest in whether the alleged economic costs of limiting emissions could be partly offset or even eliminated by use of innovative tax recycling options.

${ }^{1}$ For an Australasian perspective supporting this viewpoint see Common and Hamilton (1994) or Bertram (1994).

Robin Brasell is Environmental Adviser to the Electricity Corporation of New Zealand. 
Weyant (1993) summarised results from 14 modelling groups of the 12th Stanford Energy Forum who examined this topic. Where target emission reductions are required within a decade or so, recycling carbon tax revenues by reducing less efficient taxes was described as diminishing but generally not eliminating the cost of control. As well, recycling through low-return government projects was considered substantially to increase the costs of carbon emission reductions. More recently, considerable research effort has been directed towards developing multi-disciplinary integrated assessment models.

\section{Burden Sharing Between Countries}

To stabilise atmospheric $\mathrm{CO}_{2}$ concentrations at some agreed level requires the nations responsible for the great bulk of global emissions to take steps to abate them. Individual countries have very different emission characteristics and hence incur different abatement costs. To encourage abatement, participant countries must be assured that the burden they are asked to assume is fair.

The FCCC contains many references to international equity, especially but not exclusively directed towards protecting the interests of developing nations. It sets out developed country parties' obligations to formulate policies and measures to limit emissions of greenhouse gases and protect and enhance sinks. It is made very clear that the policies and measures should be

... taking into account the differences in these Parties' starting points and approaches, economic structures and resource bases, the need to maintain strong and sustainable economic growth, available technologies and other individual circumstances, as well as the need for equitable and appropriate contributions by each of these (developed country) Parties to the global effort regarding that objective. (United Nations, 1992:Article 4, 2(a))

Recent studies suggest that Australia and New Zealand may have to sacrifice more than most OECD nations to reduce $\mathrm{CO}_{2}$ emissions (Hanslow et al., 1994). Chisholm and Moran (1994) attribute the high cost of Australia's emission stabilisation to its high level of emissions growth and the importance of its energy-intensive traded sector. These factors are partly offset by a range of low-cost fuel substitutes in the electricity sector. In contrast, New Zealand has a preponderance of hydroelectricity generation, meaning that fewer emission reduction opportunities from fossil-fuel substitution exist. A greater proportion of emission reductions must therefore be made from the transport sector. Energy-intensive food and rawmaterial processing industries like metal smelting, powdered milk and paper production are also important in New Zealand.

If the FCCC target of stabilising emissions at 1990 levels by 2000 were applied across all OECD nations, it would impose a disproportionate cost on Australia and New Zealand. Further, if the FCCC commitments were going to be made more

${ }^{2}$ For a review, see a special issue of Energy Policy 23 (4/5), 1995. 
specific or strengthened, then Australia and New Zealand would have strong cases for adopting more appropriate targets. Compared with other OECD nations, Australia has a high rate of population growth and New Zealand has an expanding planted forest estate. Hence, if additional emission reductions are required, then Australia could argue for a per capita emission target and New Zealand for use of a net emission target

\section{New Zealand's Target of Net $\mathrm{CO}_{2}$ Stabilisation}

The New Zealand government has translated its FCCC obligations into a domestic objective of stabilising net $\mathrm{CO}_{2}$ emissions at 1990 levels by 2000 and to maintain them at that level (Ministry for the Environment, 1994). The OECD's 1993-94 economic survey of New Zealand reveals that private per capita consumption in New Zealand is below the OECD average (OECD, 1994). This factor, combined with the high cost of reducing emissions in New Zealand, suggests that it is fair and reasonable to adopt a net emissions approach by using a currently high rate of plantation forest expansion to reduce the costs of initial abatement actions.

\section{Figure 1}

\section{New Zealand's gross and net $\mathrm{CO}_{2}$ emissions: millions of tonnes a year, 1990-2000}

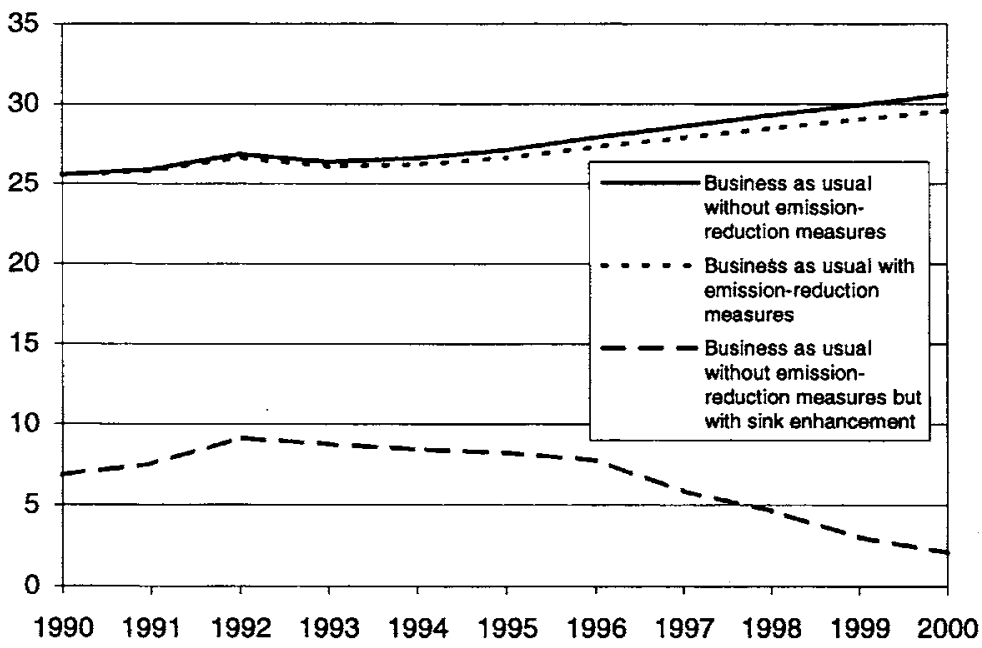

Source: Ministry of Commerce.

Figure 1 shows the projected $\mathrm{CO}_{2}$ emission paths from New Zealand's first national report to the FCCC (Ministry for the Environment, 1994). It shows the forecast reduction in the growth of emissions from pursuing various emission-reduction 
policies, principally energy efficiency initiatives and a voluntary emissions reduction scheme with industry. The government required that at least 20 per cent of the necessary net reduction for stabilisation originated from actual emission reductions, the remainder to be achieved by the enhancement of sinks. Figure 1 shows the expected trend in net emissions, assuming the given gross emissions path and sink enhancement through a (somewhat optimistic) new planting rate of 100,000 hectares a year (ha/yr) for largely radiata pine plantation forests. The date by which net stabilisation is achieved depends on emissions growth, the age-class distribution of existing forests and the actual new-planting rates. Over a few decades, maintenance of current new-planting rates could more than offset all of New Zealand's $\mathrm{CO}_{2}$ emissions.

It is sometimes argued that the expanded forest area cannot be guaranteed to remain in place in perpetuity or that soon no land will be available for forestry expansion. The Minister for the Environment counters that the joint reliance upon emission reductions and increases in carbon sinks is an interim policy to reduce the cost of whatever transition to low-carbon or renewable energy supply proves to be necessary during the next 25 to 50 years (Upton, 1994).

European Union nations have agreed to aim jointly to stabilise gross $\mathrm{CO}_{2}$ emission levels. This effectively allows for growth in emissions in some countries to be offset against (sometimes fortuitous) emission reductions from capacity decommissioning and modernisation in the former East Germany, greater utilisation of nuclear electricity generation capacity in France and the shift from coal-fired generation in the United Kingdom to high-efficiency gas-fired power stations. This illustrates the benefits of avoiding a rigid emissions reduction target for each nation and explains the inclusion of the joint implementation provisions in the Convention.

\section{Plantation Forestry in New Zealand}

The initial burst of planting during the late 1920s and early 1930s (see Figure 2) was associated with relief work schemes in place during that time. New-planting rates remained high from the early 1970 s until the mid-1980s following recognition of the value of the timber resource created. The decline in new-planting area to low levels that occurred during the late 1980s and early 1990s was brought about by a combination of factors including tax changes and the sale of cutting rights over large areas of state owned forests. Planting of new areas has increased recently because of the attraction of forestry as a superannuation investment, poor agricultural commodity returns and, especially, a period of very high international timber prices. It is expected that a new-planting rate of between 60,000 and $100,000 \mathrm{ha} / \mathrm{yr}$ will be maintained for a decade or more.

When an area is converted from clear land to a production forest, the amount of carbon stored as standing biomass steadily increases until a 'normal forest' state is achieved (Maclaren et al., 1993a). This occurs when the increase in standing carbon equals the quantity of carbon removed as logs for processing. When the forest reaches this steady state, with equal areas of all age classes, the forest has become a 
steady-state carbon reservoir. Hence the area of new forest initially operates as a carbon sink (removing carbon from the atmosphere) and ultimately becomes a steady-state carbon reservoir (no net removal of atmospheric carbon) for as long as the area remains as a production forest. The quantity of carbon stored as standing biomass increases with the length of the rotation period (that is, the interval between harvests). For example, a typical radiata pine commercial forest with a rotation length of 30 years stores on average 110 tonnes of carbon per hectare $(\mathrm{tC} / \mathrm{ha})$, which increases to about $151 \mathrm{tC} /$ ha with a 40-year rotation (Maclaren et al., 1993b).

\section{Figure 2}

\section{New forestry plantings and total area planted, '000ha, 1921-94}

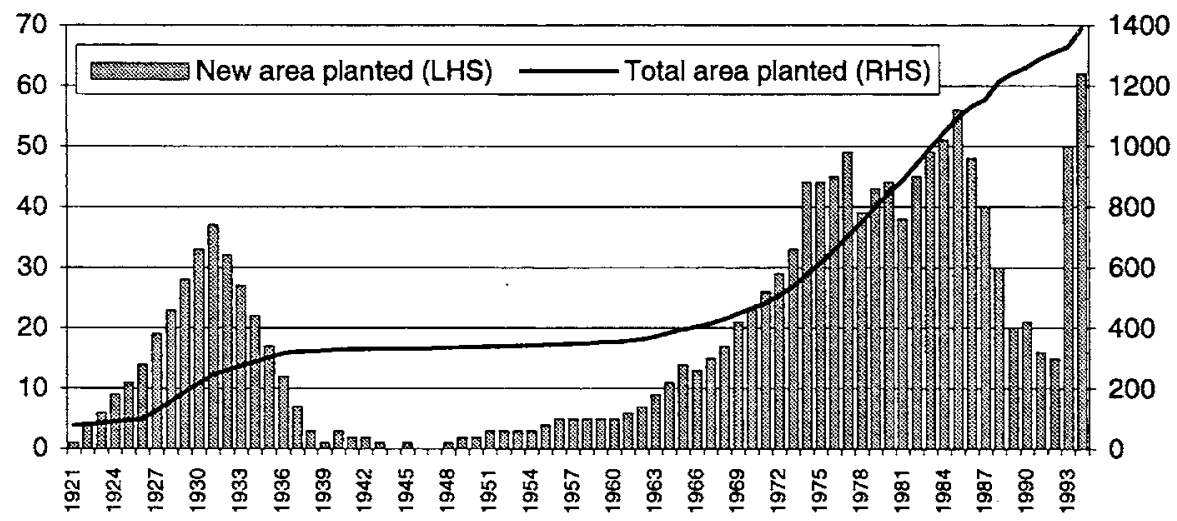

Source: Ministry of Forestry.

The uneven rate of new plantings evident from Figure 2 means that the ageclass structure is not yet stable, so that the carbon storage profile associated with production forests will fluctuate.

Wakelin and Te Morenga (1995) find that, arising from the uneven age-class distribution of the forests and a revised calculation procedure, carbon sequestration (storage) in 1990 was slightly higher than previously estimated, and hence net carbon emissions in 1990 were slightly lower at about two million tonnes of carbon a year $(\mathrm{MtC} / \mathrm{yr})$ than some earlier estimates. Another finding was that recent new planting rates, although historically high, did not meet earlier optimistic expectations; so carbon sequestration in 2000 , while still influenced by new planting rates for the rest of the decade, may be somewhat lower than the expectations included in

\footnotetext{
${ }^{3}$ One tonne of carbon is equivalent to 3.67 tomnes of $\mathrm{CO} 2$.

${ }^{4}$ For the methodology of calculating carbon storage from production forests, see Ministry for the Environment (1994).
} 
New Zealand's first national report to the FCCC (Ministry for the Environment, 1994).

One effect of the uneven age class of New Zealand plantation forests is to lower the carbon sequestration rate during the middle of the present decade relative to the beginning and the end. This effect, and the revisions to carbon sequestration described above, delay the date of achieving stabilisation of net $\mathrm{CO}_{2}$ emissions in New Zealand. Whether this is achieved by 2000 or several years after will depend on the actual emission growth, the new-planting rates and harvesting management practices that occur during the rest of the decade. If new-planting rates remain near present levels, then annual carbon sequestration by 2010 could exceed ten $\mathrm{MtC} / \mathrm{yr}$, resulting in New Zealand making no net contribution to atmospheric $\mathrm{CO}_{2}$ levels.

Wakelin and Te Morenga (1995:15) summarise the position as follows:

.. . plantation forestry in New Zealand provides a substantial carbon offset for fossil fuel emissions. It will continue to do so for as long as unforested land is converted to forest at rates similar to those taking place over the last few years. There is sufficient plantable land in New Zealand to maintain this high rate of sequestration for 50 to 100 years. Whether afforestation is a 'short-term' or 'medium-term' benefit to New Zealand's position, is merely one of definition.

Given the reference in the FCCC to sinks and sources, the greater significance of sinks than of sources and the likely high costs of reducing emissions in New Zealand, then it is not surprising that New Zealand has adopted a net target for stabilisation of $\mathrm{CO}_{2}$ emissions.

\section{$\mathrm{CO}_{2}$ Regulation under the Resource Management Act}

The use of natural resources in New Zealand is governed by the Resource Management Act 1991, whose goal is the sustainable management of natural and physical resources. Since the Act defines actual or potential environmental effect very broadly, possible climate-change effects from $\mathrm{CO}_{2}$ emissions are considered during consent hearings to obtain discharge permits for significant emitting industries. The Act is administered at a regional level by territorial local authorities. Various mechanisms within the Act allow central government to influence decisions made during the consent-granting process. These include: use of a national policy statement; call-in of the consent application for hearing by a Board of Inquiry appointed by the Minister for the Environment, who then decides on the application; promulgation of standards; making submissions at consent hearings; and providing nonbinding guidelines for local authorities.

Climate change has become a major issue at consent applications or renewals for significant fossil-fuel using industries. Some interesting views have been expressed at these hearings. For example, at the ECNZ-owned Huntly gas/coal-fired power station consent renewal (Waikato Regional Council Hearings Committee, 1993), Greenpeace argued that the net approach was not allowed under the FCCC 
and that the consent authority should use the opportunity to cap emissions from the station. However, the Maruia Society, a national environmental organisation, argued that the Resource Management Act should be interpreted as requiring full mitigation of $\mathrm{CO}_{2}$ emissions from the station, and that this should be provided by requiring ECNZ to plant additional forests. ECNZ argued that sufficient plantings were already occurring to ensure that New Zealand would meet its FCCC obligations; and, in the absence of any government directive that was binding under the Act, no specific $\mathrm{CO}_{2}$ condition was necessary.

In its consent, the Waikato Regional Council did not impose a tree-planting requirement, but did include regular 'best practicable option' (BPO) tests (in effect, efficient technology reviews) for $\mathrm{CO}_{2}$ emissions, along with periodic review of conditions against any instrument recognised under the Act that the government might use to promulgate a consistent national policy. The Council also recommended that the government develop directives to ensure that actions taken to meet New Zealand's international obligations were comprehensive and that the use of economic instruments should be considered. Clearly, the consent authority felt that the present situation of ad hoc consideration of $\mathrm{CO}_{2}$ emissions in consents, without clear guidance from the government in a form that had weight under the Act, was unsatisfactory.

The most controversial consent application from a $\mathrm{CO}_{2}$ viewpoint was ECNZ's application for an air discharge permit for the proposed $400 \mathrm{MW}$ gas-fired Taranaki Combined Cycle (TCC) power station. The Minister for the Environment, Simon Upton, used the call-in provisions of the Act because he considered the $\mathrm{CO}_{2}$ implications of the project were of national significance. A Board of Inquiry consisting of a Queen's Counsel, a professor of engineering and a Taranaki regional councillor was convened, and heard submissions from a large number of interested parties, in the manner of ordinary regional hearings. The most substantial submissions from environmental organisations were once again from Greenpeace and the Maruia Society. The Board of Inquiry's (1995) recommendation to the Minister included the findings that the proposed $\mathrm{CO}_{2}$ discharge was of sufficient magnitude to be relevant to New Zealand's FCCC obligations, that alternatives to the discharge had not been satisfactorily examined, and that tree planting was a feasible mitigation option. The recommended consent included a condition requiring the consent holder to establish a carbon sink of sufficient size to store in perpetuity an equivalent quantity of carbon to that released from the plant during the term of the permit. This would have required establishing about 3,500 ha of additional plantation forest for each year that the station operated.

The Minister, when granting the consent in March 1995, generally accepted the Board's recommendations, but allowed more flexibility than did the Board in determining how full mitigation of $\mathrm{CO}_{2}$ emissions was to be achieved. As well, the mitigation obligation applied only when cmissions from the electricity sector exceeded the level reached just before the plant began operation. This allowed the consent holder to receive some benefit from the $\mathrm{CO}_{2}$ savings associated with the displacement of other, less efficient, generation. The TCC project, and hence the 
consent obligations, were subsequently sold to a consortium that included Trans Alta, a Canadian utility, and Fletcher Challenge, a New Zealand-based company with extensive energy and forestry interests.

A recent consent hearing for a process with significant $\mathrm{CO}_{2}$ emissions involved Mercury Energy's 105 MW Southdown combined cycle station proposal in Auckland. The Minister chose not to call in this consent for a number of reasons outlined in the submission made on his behalf at the hearing (Ministry for the Environment, 1995). These reasons included the extent to which the emissions were nationally significant, the timing of the hearing, and the expectation that the Board of Enquiry report and the Minister's decision on the TCC consent would have some precedence value. The Auckland Regional Authority (1995), when issuing its decision, did not accept the arguments of the Ministry for the Environment and the Maruia Society to the effect that that TCC consent-type principles should be applied. The key elements of the consent were a BPO-type condition similar to that applied to the Huntly power station and the possibility of more $\mathrm{CO}_{2}$ conditions following review if the government issued an appropriate instrument.

\section{Implementing $\mathrm{CO}_{2}$ Policy Outside the Act}

The government policy relies jointly on $\mathrm{CO}_{2}$ emission reductions and carbon sink enhancement in a ratio of at least 1:4. The measures planned to provide the required emissions reductions are outlined in detail in New Zealand's first national communication required under the FCCC (Ministry for the Environment, 1994). The key emission reduction measures are: energy sector reforms; an energy efficiency strategy managed by the Energy Efficiency and Conservation Authority (EECA); further development of renewable energy sources, also managed by EECA; and a voluntary agreements (VA) scheme with industry to reduce emissions. There are parallel policies to enhance carbon storage.

The most relevant policy for industry is the VA scheme. The agreements signed in September 1995 with nine industries, including ECNZ, are expected to lead to an accumulated reduction in $\mathrm{CO}_{2}$ emissions during the present decade of about two millions of tonnes of $\mathrm{CO}_{2}$ a year $\left(\mathrm{MtCO}_{2} / \mathrm{yr}\right)$. Additional agreements have been signed and it is expected that the total savings could approach three $\mathrm{MtCO}_{2} / \mathrm{yr}$.

During a climate-change policy review in 1994, some industries strongly supported the VA approach to $\mathrm{CO}_{2}$ reductions, while some officials favoured applying a carbon tax. The effectiveness of the VA scheme and the other initiatives will be examined by the government late in 1996. If it appears that New Zealand will not achieve its net stabilisation target, or if the contribution from emission reductions is less than the 1:4 requirement, then use of a carbon tax or some other economic instrument is likely. The review process is not widely understood, but if the VAs actually achieve their stated targets, then the 1:4 requirement should have been met. 


\section{New Zealand's Policy Problem}

The key problem with the climate change policy from an industrial viewpoint is that $\mathrm{CO}_{2}$ issues are governed by two or even three regulatory instruments: the resource consent process, the separate VA scheme, and, potentially, use of a carbon tax following the 1996 review. This increases compliance costs for industry and creates uncertainty, which is a significant disincentive for investment in industrial capacity. In addition, the approach to air discharge permits issued for major $\mathrm{CO}_{2}$ sources has been inconsistent.

Regional government also experiences difficulty when making consent decisions for significant $\mathrm{CO}_{2}$ emission sources. In the absence of an instrument recognised under the Resource Management Act, ministerial submissions at a consent hearing are considered alongside, and with equal weight to, submissions made by other interested parties. Regional councils have consistently requested the government to deliver clear guidance as to how $\mathrm{CO}_{2}$ issues should be dealt with at the regional level, and have been reluctant to follow the minister's example in the TCC decision in requiring specific mitigation. Generally, the decisions have required that a BPO test be regularly undertaken for $\mathrm{CO}_{2}$ emissions and that a clear review provision be made available in case the government issues clear and binding guidelines. The result is an intense focus on $\mathrm{CO}_{2}$ emissions that originate from industry and correspondingly little attention to emissions from numerous diffuse transport sources, as well as the significant contribution from agricultural methane $\left(\mathrm{CH}_{4}\right)$ and nitrous oxide $\left(\mathrm{N}_{2} \mathrm{O}\right)$. Consequently, New Zealand's present domestic climate-change policy is neither comprehensive nor equitable.

The Minister for the Environment has on several occasions indicated that the Resource Management Act is not the best instrument for regulating $\mathrm{CO}_{2}$ emissions. But he is faced with several difficulties. If he continues to rely upon the Act, but increases certainty by issuing a national policy statement, then the process could be very involved and cumbersome. The final outcome is also appealable to the Planning Tribunal on matters of fact or further on points of law. This means that government policy could be directly amended by the Courts. And if individual consents are still dealt with under the Act at a regional level, different interpretations of the guidance provided will still occur.

Another option is to remove $\mathrm{CO}_{2}$ issues from the Act and to deal with them under separate legislation at a national level. But the government cannot guarantee that such legislation would be passed in parliament. The major opposition parties, Labour and the Alliance, have expressed reservations with the net approach to $\mathrm{CO}_{2}$ emission limitation; and the Alliance is committed to a carbon tax.

The Minister's response to the present impasse has been to assemble a Working Group on $\mathrm{CO}_{2}$ Policy, comprising officials and four individuals from the private sector. Three of the latter have senior management experience in the energy and forestry sectors, while the fourth is executive director of a national environmental organisation. The working group's task is to ensure that New Zealand's $\mathrm{CO}_{2}$ objectives are met as cost-effectively as possible. The principal issues they are examining include the problems with the Resource Management Act's case-by-case approach, 
carbon storage, the effect on emission growth of different GDP growth assumptions, and the most efficient economic instrument should one be required following the 1997 review. The group's brief is to analyse and present the issues in a form that facilitates public debate, to prepare a discussion document (Ministry for the Environment, 1996), and then to receive and summarise public submissions in the second half of 1996.

\section{An Efficient Means of Integrating Sources and Sinks}

Minimising the costs of control under New Zealand's net approach to emissions reduction requires a system that efficiently integrates sinks and sources. Clearly, use of the Resource Management Act as a means of limiting those emissions presently covered by the Act does not meet the efficiency test. The ad hoc mitigation obligations imposed in the TCC consent allowed some flexibility of response but discriminated between sources.

If the 1997 review reveals the need for further action to reduce emissions, the likely candidates are a carbon tax or a tradable permits regime. In an analysis undertaken for ECNZ of a tradable permit system that includes carbon credits from expanding forests, as well as emission permits, the Tasman Institute (1994) concluded that New Zealand had a comparative advantage in sink enhancement and that high rates of new planting would represent an international business opportunity.

In addition to the textbook options of taxing emissions and subsidising sinks or establishing a carbon market, opportunities exist for mixed or hybrid approaches that allow for integration of sources and sinks. A simple approach could involve a carbon tax but allow the industry to pay the tax, purchase a permit from another party in lieu of the tax, or even undertake some mitigation actions. The latter might include energy efficiency improvements, on-site or elsewhere, and tree planting, which could then be registered in exchange for permits. A forest company could then choose to manage its forests so as to maintain a certain level of carbon storage as verified by an authority, and to register the carbon storage property that could then be traded for value, while accepting an offsetting liability should carbon storage levels fall below the contracted level. These obligations could be long-term in exchange for a perpetual right, or for a finite period. Such an approach is preferable to treating every commercial harvest of a production forest as a $\mathrm{CO}_{2}$ emission and regarding every new planting or re-planting as a carbon store. This general approach removes one of the major uncertainties of tradable systems, namely, the risk of an unexpected high price following an error of judgment or an exercise of market power by another participant because the permit price is effectively capped at the tax rate. It also provides an additional incentive to actively pursue lowest-cost responses.

\section{Conclusions}

It is generally accepted that achieving $\mathrm{CO}_{2}$ emission reductions involves economic costs, especially if reductions are required in the lifetime of affected capital plant. Innovative tax recycling options can be expected to reduce these costs. Australia and 
New Zealand appear to be among the more expensive OECD nations in which to reduce $\mathrm{CO}_{2}$ emission levels. The FCCC clearly intends that no party should bear an unfair or disproportionate burden and that its measures should be of least cost. New Zealand's adoption of a net $\mathrm{CO}_{2}$ stabilisation is consistent with the FCCC's intention that each nation adopt measures that best fit its own circumstances, which for New Zealand at present includes a comparative advantage in the establishment of commercial plantation forests.

New Zealand's current domestic climate-change policy has problems. For example, control of industrial emissions is uncertain, being implemented through the consent process under the Resource Management Act and through a voluntary agreements scheme, while vehicle emissions and other greenhouse gas emissions from agriculture effectively are not controlled in any way. The Minister for the Environment recognises the unsuitability of leaving $\mathrm{CO}_{2}$ issues in the Act, and has convened a joint public- and private-sector working group to review future policy options.

New Zealand should not move beyond no-regrets or very low-cost actions unless it becomes clear that net stabilisation of emissions will not occur during the first few years of the 21 st century. But if additional measures are required, then a cautious approach should be adopted with a particular emphasis on the cost implications because New Zealand appears to be a relatively expensive country in which to reduce emissions. Any additional measures that are required should also recognise New Zealand's comparative advantage in the provision of carbon sinks. Thus the key issue is the efficient integration of sources and sinks in a way that allows maximum flexibility of response for participants so as to eliminate any unnecessary costs.

\section{References}

Auckland Regional Council Hearings Committee (1995), Decision on the Southdown Cogeneration Ltd. air-discharge permit, Regional House, Auckland (28 April).

Bertram, G. (1994), 'Modelling the Effects of the Use of Economic Instruments to Reduce Carbon Dioxide Emissions', paper presented to Greenhouse 94, Wellington (October).

Board of Inquiry into the proposed Taranaki power station - air discharge effects (1995), Report and recommendations (February).

Chisholm, A. \& A. Moran (1994), Carbon Dioxide Emissions Abatement and Burden Sharing Among the OECD Countries, Tasman Institute, Melbourne (Occasional Paper B 26).

Common, M. \& C. Hamilton (1994), 'The Economic Consequences of Carbon Taxation in Australia', paper presented to Greenhouse 94, Wellington (October).

Hanslow, K., M. Hinchy \& B. Fisher (1994), 'International Greenhouse Economic Modelling', paper presented to Greenhouse 94, Wellington (October).

Maclaren, J., D. Hollinger, P. Beets \& J. Turland (1993a), 'Carbon Sequestration by New Zealand's Plantation Forests', New Zealand Journal of Science 23(2): 194-208. 
Maclaren, J., S. Wakelin \& P. Beets (1993b), Projected Carbon Sequestration by Forest Plantings Commencing in 1991, Forest Research Institute report for Ministry of Forestry, Rotorua (June).

Ministry for the Environment (1994), Climate Change: The New Zealand Response, New Zealand's First National Communication under the FCCC, Wellington (September).

(1995), Submission made on behalf of the Minister for the Environment to the Auckland Regional Council/Auckland City Council hearing into the application by Southdown Cogeneration for an air discharge permit, Regional House, Auckland (5 April).

(1996), Climate Change and COr Policy: A Durable Response, Discussion Document of the Working Group on $\mathrm{CO} 2$ Policy, Wellington (June).

Organisation for Economic Cooperation and Development (OECD) (1994), OECD Economic Surveys 1993-94: New Zealand, Paris.

Tasman Institute (1992), The Economic Effects of Reducing Carbon Dioxide Emissions, Melbourne (Research Report No. C2).

(1994), Carbon Dioxide Emissions Abatement and Burden Shaning among the OECD Nations, Melbounie (Occasional Paper B26).

United Nations (1992), United Nations' Framework Convention on Climate Change, New York.

Upton, S. (1994), Address to seminar on the government's CO2 policy package, Wellington (14 September).

Waikato Regional Council Hearings Committee (1993), Decision on the Huntly Power Station air discharge permit (16 December).

Wakelin, S. \& L. Te Morenga (1995), Carbon Sequestration by Plantation Forests: Calculations Revised as at June 1995, Forest Research Institute report for Ministry of Forestry and Ministry for the Environment (July).

Weyant, J. (1993), 'Costs of Reducing Global Carbon Emissions', Journal of Economic Perspectives $7(4): 27-46$.

Comments provided by colleagues and two anonymous referees are gratefully acknowledged. 